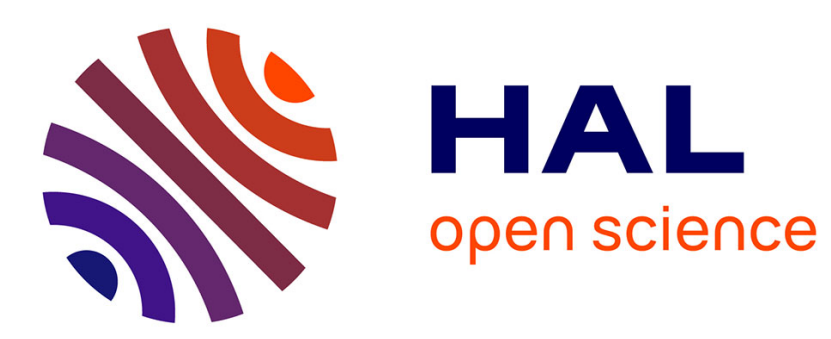

\title{
The impact of digital technologies on perceptions of proximity
}

Bastien Bernela, Marie Ferru, Alain Rallet

\section{To cite this version:}

Bastien Bernela, Marie Ferru, Alain Rallet. The impact of digital technologies on perceptions of proximity. 2019. hal-02051751

\section{HAL Id: hal-02051751 \\ https://hal.science/hal-02051751}

Preprint submitted on 28 Feb 2019

HAL is a multi-disciplinary open access archive for the deposit and dissemination of scientific research documents, whether they are published or not. The documents may come from teaching and research institutions in France or abroad, or from public or private research centers.
L'archive ouverte pluridisciplinaire $\mathbf{H A L}$, est destinée au dépôt et à la diffusion de documents scientifiques de niveau recherche, publiés ou non, émanant des établissements d'enseignement et de recherche français ou étrangers, des laboratoires publics ou privés. 


\title{
The impact of digital technologies on perceptions of proximity
}

\author{
Bastien Bernela*, Marie Ferru*, Alain Rallet*
}

Draft, January 2019

\author{
* CRIEF, University of Poitiers, bastien.bernela@univ-poitiers.fr \\ ** CRIEF, University of Poitiers, marie.ferru@univ-poitiers.fr \\ *** RITM, University of Paris Sud, Paris Saclay, alain.rallet@u-psud.fr
}

\section{Introduction: from objective to perceived proximity}

The approach developed by the research group "Proximity Dynamics" (RERU, 1993) seeks to avoid reducing space to distance and transportation costs (Bellet et al., 1998), and to deliver a qualitative characterization of distance through a more complex understanding of proximity. In an attempt to enrich the concept of proximity and expand it to embrace various forms of coordination, the authors introduce different types of proximity (Torre and Rallet, 2005; Boschma, 2005). The concept of proximity thus loses its exclusively geographical character, and needs to be distinguished from the notion of co-location.

In this context, the authors of the group have from the very outset stressed the crucial importance of perceptions of space. However, this latent program has not been kept in most subsequent empirical contributions by the "Proximity Dynamics" group, where a tendency towards objectivism (i.e. the assignation of proximity to pure objective contents) can be observed. Literature on proximity thus generally measures objective forms of proximity, although perceived proximity is also important in explaining actors' behaviors. Perception issues are crucial to understand socio-economic coordination issues arising between actors; for instance, this question is at the heart of the debate in the geography of innovation, when discussing constraints affecting interactions between partners in collaborative projects. From this perspective, we examined the growing development of digital technologies and the ways in which it can affect the actors' behavior (namely, the way they interact) and their perceptions of proximity (looking for instance at the increasing ease with which people can interact remotely).

The objective of this chapter is to analyze the impacts of the current digital revolution on proximity through the changes it brings about in the perception of proximity. In this chapter, we mainly focus on the perception of geographical proximity.

The first section is dedicated to an analysis of the perception of geographical proximity. We suggest that three determinants can affect this perception: distance obviously, but also constraints related to F2F interaction, as well as the effects of non-geographical proximity. In this perspective, we examine different types of literature - geography, sociology and psychology -, highlighting the contributions and evolutions brought by the multidisciplinary work of the group "Proximity Dynamics". The second section shows how the development of 
ICT has modified the perception of geographical proximity through its impact on these three determinants. We review literature on this issue among studies on proximity and related works. Finally, in the third section, we address an open issue by taking into account the impacts of the most recent generation of digital technologies on spatio-temporal representations of proximity. This leads us to propose a new concept of proximity: "proximity on the move", at the crossroads of mobility and proximity.

\section{Geographical proximity as perceived proximity}

As various social sciences have shown, the position of actors in space is not only a matter of rationality and objective factors but also a matter of how these actors represent themselves. The work of the "Proximity Dynamics" group forms part of this trend, as it highlights the importance of perceptions of space.

According to literature on this topic, the perception of geographical proximity is mainly based on three elements: distance, face-to-face constraints and feedback effects between types of proximity.

a) First of all, the perception of proximity is related to distance, which itself depends on the perception of movement. On this first point, according to "proximist" literature, distance is relative to transportation costs and time. From this perspective, Torre and Rallet (2005) consider that two actors are considered as close if they can meet physically every day. A 300 $\mathrm{km}$ train journey between two cities may be faster than going from the south to the north of a metropolitan area. According to the authors, geographical proximity is also related to the assessment made by individuals, which consists in considering all the parameters that influence distance. This set of parameters includes objective data $(\mathrm{km}$, time, price) but also the perceptions held by individuals (Torre and Rallet, 2005). Proximity is for instance related to the stress experienced as a result of distance (Bourdeau-Lepage and Huriot, 2009): the possibility of meeting once a day may be perceived differently depending on the person, his/her age, social group, gender, occupation, etc. For the first time, such works finally presented the intuition that perceptions matter; however, in their further empirical developments, the authors propose an axiomatic measure (near vs. distant) or an objective one ( $\mathrm{km}$, time, costs) that negates their initial insights.

The analysis of perceptions of distance has been further developed by other social sciences and primarily by geographers, although this discipline mainly focused on the physical materiality of space. Building on the one hand on Simon's thesis on limited rationality and on the other on psychologists' work on cognitive biases, American geographers developed the "geography of perception" in the 1950s (Golledge, 2008; Gould and White, 1974). In the 1970s, French geographers also argued for a geographical analysis focused on the perception of space (Frémont, 1974, 1976; Claval, 1974; Bailly, 1977, 1986, 1990), leading to numerous debates on the relationship between subjective and objective categories of space.

The "geography of perception" is basically based on the idea that an individual perceives information depending on previously acquired knowledge and experience, which in turn have been built from previous actions or perceptions. This transformation of information produces 
a subjective representation of reality, which influences individual decisions (Zenker, 2007). The emphasis is placed on cognitive aspects and interactions between the individual and the social context within a territorial context. In methodological terms, the "geography of perception" uses various methods from declarative questionnaires to the examination of novels, speeches, reports and practices that provide complementary representations of space. Cartography as an instrument was adapted to integrate the perception of distances through anamorphic maps; mental maps were also developed as a subjective spatial investigation model (Gould and White, 1974).

More recently, a relatively abundant literature has developed on the geography of transport (De Vos et al., 2013), expanding the scope of the perception of distance to include well-being. Authors seek to measure the levels of well-being associated with movement (i.e. the concept of "satisfaction with travel scale" (De Vos et al., 2015)) and to analyze the explanatory factors associated with this well-being; and conversely, the impact of distance on the general wellbeing of individuals or on transport-related behaviors such as modal choices (De Vos and Witlox, 2017).

b) Once the distance has been traveled (i.e. the co-location has been made possible, at least temporarily), authors agree that physical contact provides an incomparable sensory perception of the actor you are coordinating with (for instance, a partner in a research collaboration). As explained by Urry (2002), "historically, the social sciences have overly focused upon ongoing geographically propinquitous communities based on more or less face-to-face social interactions between those present". This conventional wisdom is based on the assumption that it is difficult to develop effective teamwork at a distance without any significant "facetime" (Winger, 2005), considering the various advantages of face-to-face (F2F) interaction. This is because 1) F2F mitigates problems to do with incentives and free riding since it is easier to observe and interpret a partner's behavior in a F2F situation. 2) F2F interaction promotes the development of trust, based on reputation effects (Gambetta, 1988; Lorenz, 1992). 3) F2F interactions offer "an unusual capacity for interruption, repair, feedback, and learning" (Nohria and Eccles, 1992, p. 292). 4) Tacit knowledge can easiest be transmitted in a F2F context, which justifies the co-location of innovative firms (Maskell and Malmberg, 1999).

This F2F thesis was relatively well developed by the authors of the "Proximity Dynamics" group. They specify that F2F interactions are all the more crucial for some specific tasks: for knowledge-intensive activities such as innovation processes, the more tacit the shared knowledge is and, the more F2F is required (Aguiléra and Lethiais, 2011). In addition, the more frequent the interactions between partners and the greater the need for F2F contact. As these characteristics (tacit knowledge, frequency of interactions) vary according to the innovation cycle, the F2F constraint depends on the stage of the project (Torre and Rallet, 2005; Gallié and Guichard, 2005). An in-depth case study of technology transfer in the biotechnology sector by Gallaud and Torre (2004) confirms these findings and reveals that for most partnerships, interactions are frequent during partner search and contract negotiation especially when actors have very different knowledge bases and the project is loosely structured. 
This F2F thesis has also been augmented by non-proximist research developed for instance by Bathelt et al. (2004), Bathelt and Turi (2011), or Storper and Venables (2004). The latter authors interestingly highlighted four main features of F2F interaction: it provides an efficient communication technology; it can help solve incentive problems as well as facilitating socialization and learning; and it provides psychological motivation. These authors also specify how F2F can be crucial in environments where information is imperfect, rapidly changing and not easily codified. In this context, "corporeal proximity in diverse modes appears to make travel necessary and desirable" (Urry, 2002): the F2F thesis therefore justifies the actors' mobility. Indeed, mobility involves occasional, intermittent face-to-face conversations and meetings within certain places at certain moments that seem obligatory to some or all of the participants (...) To maintain trust, people need to - at least intermittently meet and experience the effervescence of this collaborative live performance (ibid.).

c) The perception of geographical proximity is also determined by the existence (or the absence) of other forms of proximity. Researchers have found that physical proximity explains no more than half of a person's feeling of "subjective distance" (Coshall and Potter, 1987). This depends on the context in which the situation is performed as defined by Goffman (1991) - i.e. a form of representation of reality that guides individuals' perceptions. This work, initially developed by psychologists, echoes recent developments in management studies (Wilson et al., 2008; O' Leary et al., 2014; etc.), which define "perceived proximity as a dyadic and asymmetrical construct that reflects one person's perception of how close or how far another person is" (Wilson et al., 2008, p. 1222). Research later examined the paradoxical phenomenon of the "Far-but-Close » and its contrary the "Close-but-Far » (Wilson et al., 2008). This paradoxical phenomenon refers to the notion that a person can feel quite distant despite being in close physical proximity, while another may seem quite close although he or she is far away in objective terms. The authors argued that one can perceive proximity differently depending on each individual's relative situation. The findings obtained by these research projects suggested that distance does not affect the quality of relationships in geographically distributed teams but perceived proximity does.

Proximist literature enriched this debate with an empirical dimension through the notion of "activating geographical proximity". Geographical proximity is not perceived as such if it is not activated by non-geographical proximity. For instance, Aguilera et al (2015) show that some firms declare that proximity played a role in their cooperation with a partner when the partner was geographically distant and, conversely, that proximity did not matter when the partner was geographically close. To be close to someone is not only to be next to him/her, but it can also mean having a strong connection with a geographically distant person, whether they belong to the same circle of friendship, family or business, or professional network (Torre and Rallet, 2005). Strong organized (or relational) proximity can not only "compensate" for geographical distance but also impact the perception of geographical proximity itself. This thesis of the non-independence of proximity enables authors to take into account the role of perceptions: the perception of geographical proximity is altered by other forms of proximity (Amin and Cohendet, 2004; Torre and Rallet, 2005) and by the past construction of their combination (Ferru, 2009). For instance, geographical proximity is less necessary if partners in an innovative project share the same field of knowledge (cognitive 
proximity), are embedded in the same social network (relational proximity), belong to the same organization or community (organizational proximity) or are immersed in the same system of values (institutional proximity). These various types of proximity do not remove the need for geographical proximity but minimize the perception of its importance. This leads many authors to distinguish between actual and activated geographical proximity (Torre, 2014).

This interdisciplinary literature review allowed us to highlight three determining factors in the perception of geographical distance. The next section will examine the crucial and growing role of ICT, and its impact on perceived forms of proximity.

\section{Impacts of ICT on perceived proximity}

In literature on proximity, this factor has been mainly addressed as a coordination issue (see the critical survey carried out by Rallet and Torre, 2017). As a result, ICT has been considered as means of communication enabling economic agents to better coordinate across different locations (Galliano and al., 2011). This gave rise to a debate about ICT's ability to lift the constraint of physical proximity to support certain interactions (Aguilera and Lethiais, 2011). A radical but also more naive approach raised the question of whether ICT would announce the end of geography (O' Brien 1990 \& 1992, Cairncross, 1997), or in other words the end of the constraint of physical proximity. Criticism of this thesis (Morgan 2004, Torre and Rallet, 2005) has given rise to many theoretical and empirical works since the 90s.

This section will outline the main directions and findings of these works. Their conclusions converge on the need to maintain face-to-face (F2F) relations on the one hand, and on the geographical extension of remote coordination on the other. It is interesting to note that reaching these conclusions involved taking into account the subjective dimension of proximity. We show this using the analytical framework presented in section 1 . However, this literature considers the impact of digital technologies from a limited and somewhat outdated point of view. Limited, because it is restricted to coordination problems within production or innovation processes. Outdated because it does not take into account new generations of technologies that are deeply changing relations to space. The second part of this section examines how these limits are interrelated.

\section{2-1 The impacts of ICT on the three dimensions of perceived proximity}

What are the impacts of ICTs on the perception of geographical proximity? In other words, what are its impacts on the factors that explain this perception: objective distance, the requirement of F2F contact, and the intensity of non-spatial proximity?

a) On distance

ICT is mainly considered as a means of coordination. As such, it makes coordination easier by providing communication tools (telephone, e-mail, professional messaging, videoconferencing, etc.) and access to corporate information systems (intranet or extranet) and databases, whether for long-distance or short-distance coordination. In earlier literature 
on the relation between ICT and distance - i.e. studies published between the $80 \mathrm{~s}$ and the beginning of this century -, ICT was considered as having no effect on the perception of physical distance because, as a (new) means of coordination, it was supposed to compete with another well-known way of coordinating in physical space: travel. The question was to what extent ICT could replace travel as a means of coordination. (Moktarian, 2009). Most empirical papers showed that ICT could not provide a substitute for most professional trips but that it did in itself induce new reasons to travel (on this literature, see for instance the survey conducted by Aguilera and al., 2009). In terms of perception, this means that distance matters as much as it did before, even if ICT changed the nature of the activities for which distance remained necessary. For instance, some meetings can now be held remotely using videoconferencing (substitution effect), but the development of remote coordination induces new reasons for moving to solve interaction issues that require face-to-face relations (complementarity effect).

b) On F2F

As shown previously, the need for F2F interaction in literature on proximity is mainly analysed in innovation studies. It is explained by the tacit share of knowledge involved in processes while codified knowledge, which is disembodied from individuals, can more easily be transmitted at a distance (Cowan and Foray, 1997). During this period, ICT was represented as a tool used for formalizing coordination routines (e.g. written communication) and objects (e.g. shared databases). As a result, the use of ICT was associated with a codification of coordination. This implicit association (linked to representations of ICT that were predominent at the time but not perceived as such) led to a simple conclusion: ICT tends to reduce the need for face-to-face contact only if it makes it possible to codify a larger part of the knowledge incorporated in the innovation process by digitizing it. In this case, ICT enhances the possibilities of remote communication. But insofar as innovation constantly recreates tacit knowledge in the emergence stage of projects, F2F is required because ICT is not suitable for the transfer of tacit knowledge (Torre, 2008).

c) On non-geographical proximity

ICT reinforces the effects of non-geographical forms of proximity on perceived proximity by lowering the cost of their channels (e.g. the global pipelines, see Bathelt et al. 2004): digitization of shared cognition, strengthening of geographically dispersed social ties (community effect) or distant organizational links (messaging, information systems), diaspora effect (sharing cultural values throughout geographical areas).

By reducing the need for F2F contact at certain stages of innovation projects and by increasing the power of non-spatial proximity to overcome distance barriers, ICT tends to decrease the perceived importance of the constraint of physical proximity. However, these technologies do not upset spatial patterns. They only accentuate past trends: geographical proximity continues to matter through co-location or temporary proximity, but remote coordination appears on the rise.

\section{2-2 From ICT to the digital era: new perceptions of proximity}


The impacts of ICT were mainly analyzed as the effects of the means of coordination between given locations on dyadic or bilateral relations. However, nowadays, the impacts of the digital cannot be reduced to the effects of coordination means applied within a dyadic framework between predefined locations. Digital technologies and markets are i) developing multilateral platform-based coordination, ii) transforming our relationship to space-time with the development of mobile communication tools, iii) renewing the question of F2F with the development of remote co-presence and introducing other mobility issues.

i) The ability to coordinate all the stakeholders of an innovation or production project is presumably greater when these are located in a localized ecosystem than in dispersed ones, because geographic proximity reduces the transaction costs involved in establishing relationships. However, the "platformization" of industries, which is one of the central features of the digital economy, tends to lower these transaction costs independently regardless of the location of stakeholders (except for certain specific platforms such as C-to-C platforms for second-hand goods). Multilateral coordination can therefore be expected to play less in favor of localized ecosystems, even if the proximity constraint does not disappear. Little work has been done so far on the impact of digital platforms on the geography of ecosystems (see Agrawal and al. (2015) about crowdfunding platforms); this issue needs to become part of the research agenda, to assess how local ecosystem building and "translocal platforms" can be interwoven today (Bathelt and Cohendet, 2014).

ii) Mobile communication tools induce another relationship to space-time. The ability to communicate remotely and thus to coordinate at a distance was limited by the need to establish a connection from fixed locations. This is no longer the case: communication tools make it possible to continue to communicate and work from any point in space when there is network coverage. This property directly impacts the perception of geographical proximity insofar as individuals feel distant (due to geography) but at the same time close (due to their connection), whereas in the past geography imposed a binary situation: to be near or to be distant, to be there or elsewhere. In other words, co-presence is no longer the monopoly of geographical proximity: digital technologies make it possible to be both here and elsewhere to a certain extent.

iii) It should be added that, simultaneously, means of communication are becoming "warmer" thanks to new tactile and visual interfaces that deeply modify the previous generation of computer technologies marked by keyboard culture and written codification. O'Leary et al. (2014) show that even shared meaning and symbolic value between people separated by large distances can be conveyed by information systems, forming strong bonds between individuals. The need for F2F does not disappear but, because co-presence is enriched by these new media, it is no longer the preserve of geographical proximity.

Two major transformations of geographical proximity result from this change:

- What happens to the F2F constraint in this context? On the one side, F2F still matters for some interactions; on the other side, more and more interactions that previously required physical contact can be performed at a distance. This split is expected to develop in many areas, including those that traditionally involved rich human interactions (health, education, services, etc.). The perception of geographical proximity 
is divided into an irreducible component (when "thick" co-presence involves body language, facial gestures, voice intonation, etc. as stressed by Urry (2002)) and a distant component (see above, the "Far-but-Close" paradox).

- Relations between proximity and mobility must be redesigned. According to the initial configuration, mobility $\mathrm{s}$ the way of recreating a specific type of proximity: temporary proximity. But during the transportation process, any form of proximity was interrupted (except for very poor communication). Nowadays, mobile digital technologies make it possible to continue to develop interactions with remote people while on the move. We must therefore introduce, alongside temporary proximity, another type of proximity linked to mobility.

\section{3- "Proximity on the move" as a dynamic type of proximity}

The perception of geographical proximity is today affected by the development of a new form of proximity: proximity on the move. This proximity is based on mobility but in a different sense from that of temporary geographical proximity.

There is a natural and reciprocal link between mobility and proximity. But in studies on proximity, mobility has been mainly addressed from the point of view of proximity. Mobility is indeed the way of achieving a specific form of proximity: temporary geographical proximity (Torre, 2008; Bathelt H. and Schuldt, 2008). However, no contribution has so far focused specifically on the link between mobility and proximity (except for Urry (2002) who can be considered as external to this literature). In particular, there has been no analysis of proximity from the point of view of mobility. We argue in this section that i) mobility is not only a means of crossing over a distance, but also a new form of proximity that needs to be taken into account, ii) the rapid development of proximity on the move is due to a new generation of ICT that is deeply changing our relation to space and time.

\section{3-1 From temporary geographical proximity to proximity on the move}

As we have just pointed out, in literature on proximity mobility is connected to proximity, of which it is a specific form. Corporeal travel is necessary to have a F2F relationship with other people located in a different place.

\section{Figure 1: Temporary geographical proximity}

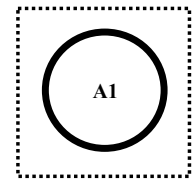

$\mathrm{t}_{1}$ : dispersed partners

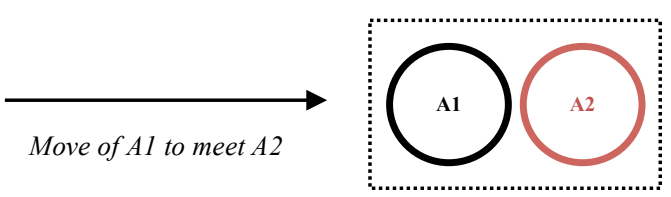

$\mathrm{t}_{2}:$ temporarily co-located partners

By analogy with comparative static analysis, we propose to define temporary proximity as a static form of proximity: it is a time interval between two locations - in the same way that comparative static analysis studies relations between two different states without analyzing the motion that leads from one to the other. In terms of temporary proximity, moving from one place to another is only a means for people to restore physical proximity when it has been broken by distance. Coordination is interrupted during the duration of travel, which is only a 
time interval between two spatial modes of coordination, between fixed locations on one side (left part of the figure 1) and within co-location on the other (right part).

Besides temporary proximity, it is necessary to consider another side of mobility defined as a dynamic form of proximity. It means that mobility is the (moving) place from which interactions with other people take place. This is made possible by the fact that trips no longer interrupt these interactions thanks to the use of mobile digital tools and communication networks (except for plane travel for the moment, but not for long). These tools and networks allow people to be continuously linked to colleagues, partners and firms by providing instant access to their resources (information, documents, databases, software, work tools...). The connection that supports interactions tends to be permanent (relying on both asynchronous and synchronous tools) and ubiquitous, subject to the conditions of network coverage. The activities performed on the move are sometimes limited by the network speed or the power and ergonomics of end-user devices. But these limitations tend to fade with broadband mobile networks and the ever-increasing power of user-friendly communication devices. As a result, almost all of a person's daily activities (including work and interactions) can be carried out during transport (Clayton, 2012, Ettema et al., 2012) or in connected places on the route called "third places" (so called because they are neither the workplace, nor the place of residence (Oldenburg, 1989)). A fundamental change has thus been introduced by the new generation of ICT: transportation can no longer be considered as lost time (Lyons and Urry, 2005). This mobility should not be restricted to the traditional mobility of professional nomads (sales representatives, maintenance engineers, consultants, etc.) whose jobs are located outside their companies. Today, it potentially affects everyone and already represents a significant share of our daily time, although transport statistics do not measure it yet.

We characterize this "proximity on the move" as a dynamic form of proximity, not only because it takes place on the move but also because its nature is temporal. Temporary geographical proximity is spatial by definition: proximity is achieved when the locations of $\mathrm{A}$ and $\mathrm{B}$ match after a displacement (see above). In contrast, the very nature of proximity on the move is temporal : the locations of $\mathrm{A}$ and $\mathrm{B}$ do not match but their temporalities do. Interactions are made possible by the permanency of this connection, not by an intermittent co-location. There is no reference to these aspects in the work of economists, but some have been developed by sociologists (Urry, 2002, and his "mobility turn"; Bauman, 2002, and his "liquid society"; Kaufman, 2002, and his neologism "motility").

\section{3-2 Impacts of proximity on the move on perceived proximity}

Considering proximity on the move modifies the three elements of the perception of geographical proximity described in the first section:

- Distance is no longer a spatial operator of separation but the moving place of a temporal proximity;

- Co-presence is no longer restricted to a spatial phenomenon but is also a temporal one (temporal continuity of co-presence, not limited to F2F); 
- The feedback effects of non-geographical proximity are reinforced: individuals are continually caught in a network of relationships that constantly solicit them (messaging, conf calls, collaborative tools...).

\section{Conclusion}

The issue of geographical proximity is too often covered in a simplistic way, considering that 1) distance is the only metrics of proximity, in a spatial/temporal separation perspective, 2) F2F requires temporary proximity to address coordination issues in the case of remote partners. ICT is consequently considered as a means of coordination, more often as a substitute to than as a complement for proximity. This chapter proposes to contribute to these recurring debates by introducing more complexity into the way geographical proximity is understood.

First, we refer to old concerns about the perception of proximity that have been progressively disregarded: proximity is not only a matter of distance but is also related to face-to-face constraints and feedback effects with non-geographical forms of proximity. Modern ICT has impacts on this perceived proximity, as the sophistication of mobile communication tools has modified our relation to space and time: the continuous connection allowed by mobile technologies invites us to consider a new form of proximity that we call proximity on the move. We define this form of proximity in a spatio-temporal and dynamic way, whereas temporary geographical proximity is only defined in a spatial and static way. Proximity on the move makes a kind of co-presence possible while the parties involved are physically distant: mobility is no longer a tool to bring temporary actors together but it becomes a dynamic environment for activity.

This analytical grid faces methodological and empirical challenges, since forms of proximity are difficult to capture in all their complexity. Conceptual advances have often been insufficiently explored empirically, because they are faced with issues to do with data availability and collection. In order to maintain the subjective character of spatial proximity, Carriou et al. (2018) propose for instance to better understand individuals' perceptions of proximity through their representations of the places in which they work or transit. Qualitative approaches and more precisely mental maps are used to capture these representations, but the large amount of collected data makes it possible for researchers to carry out quantitative treatments.

\section{References}

Agrawal A., Catalini C., Goldfarb A., 2015, «Crowdfunding: Geography, Social Networks, and the Timing of Investment Decisions ", Journal of Economics \& Management Strategy, 24 (2), 253-274

Aguiléra A., Lethiais V., 2011, «Transmission des connaissances dans les relations de coopération interentreprises : TIC versus face-à-face », Revue d'Economie Régionale et Urbaine, $\mathrm{N}^{\circ} 2,269-293$

Aguiléra A., Lethiais V., Rallet A., 2015, "Spatial Proximity and Intercompany Communication: Myths and Realities", European Planning Studies, 23(4), 798-810

Amin A., Cohendet P., 2004, Architectures of Knowledge: Firms, Capabilities, and Communities, Oxford University Press, Oxford 
Bailly A., 1977, La perception de l'espace urbain. Les concepts, les méthodes d'étude, leur utilisation dans la recherche urbanistique, CRU, Paris

Bailly A., 1986, "Subjective distances and spatial representations", Geoforum, Vol. 17 (1), $81-88$

Bathelt H., Schuldt N., 2008, «Between luminaires and meat grinders: international trade fairs as temporary clusters », Regional Studies, Vol. 42 (6), 853-68.

Bathelt H., Cohendet P., 2014, « The creation of knowledge: local building, global accessing and economic development - toward an agenda », Journal of Economic Geography, 14, 869882

Bathelt H., Malmberg A., Maskell P., 2004, « Clusters and knowledge: Local buzz, global pipelines and the process of knowledge creation ", Progress in Human Geography, 28(1), 3156

Bathelt H., Turi, P., 2011, "Local, global and virtual buzz: The importance of face-to-face contact in economic interaction and possibilities to go beyond", Geoforum, 42(5), 520-552

Bauman Z., 2000, Liquid modernity, Cambridge: Polity Press.

Bellet M., Kirat T., Largeron C., 1998, Approches multiformes de la proximité, Hermès, Paris.

Boschma, R., 2005, Proximity and innovation. A critical assessment, Regional Studies, Vol. 39: 1, 61-74.

Bourdeau-Lepage L., Huriot JM., 2009 «Proximités et interactions : une reformulation », Géographie, économie, société, Vol. 11, no. 3, 233-249.

Boutry O., Ferru M., 2016, « Les circuits courts : un modèle soutenable fondé sur les proximités ? » in P. Mundler et J. Rouchier, Alimentation et proximités : jeux d'acteurs et territoires, Dijon, Educagri editions, p9-83.

Cairncross, F. (1997), The Death of Distance, Boston, HBS Press.

Cariou C., Ferru M., Rallet A., 2018, «Perceptions des lieux et proximités subjectives : une analyse des dynamiques créatives franciliennes », Revue d'Economie Régionale et Urbaine, $\mathrm{n}^{\circ} 5-6,1121-1151$,

Claval P, 1988, An Introduction to Regional Geography, Wiley-Blackwell

Clayton W., (2012), «Is the bus boring?», Universities Transport Studies Group Conference, University of Aberdeen, UK, 3rd - 6th January, 2012., 1-12

Coshall JT., Potter RB., 1987, "Social psychological variations in the distance cognitions of urban consumers in Britain", Journal of Social Psychology Worcester, Mass, Vol. 127, $\mathrm{N}^{\circ}$ 6, 611-618.

Cowan R., Foray D., 1997, The Economics of Codification and the Diffusion of Knowledge, Industrial and Corporate Change, Vol. 6 (3), 595-622,

De Vos J., Schwanen T., Van Acker V., Witlox F., 2013 « Travel and subjective wellbeing : a focus on findings, methods and future research needs ", Transport Review, Vol. 33(4), 421442.

De Vos J., Schwanen T., Van Acker V., Witlox F., 2015, «How satisfying is the Scale for Travel Satisfaction?", Transportation Research F: Traffic Psychology and Behaviour, Vol. $29,121-130$ 
De Vos J., Witlox F., 2017, "Travel satisfaction revisited. On the pivotal role of travel satisfaction in conceptualising a travel behaviour process", Transportation Research Part A, 106, 364-373.

Ettema D., Friman M., Gärling T., Olsson L.E., Fujii S., 2012, « How in-vehicle activities affect work commuters' satisfaction with public transport », Journal of Transport Geography, Vol 24, 215-222

Ferru M., 2009, La géographie des collaborations pour l'innovation : le rôle des contraintes de ressources et de mise en relation, Thèse Université de Poitiers

Frémont A., 1974, « Recherches sur l'espace vécu », Espace géographique, tome 3, n³, 231238

Frémont A., 1976, L'espace vécu, PUF, Paris

Gallaud D., Torre A., 2004, "Geographical proximity and the diffusion of knowledge (The case of SME's in biotechnology)", In Fuchs G., Shapira P. et Koch A., Eds, Rethinking Regional Innovation, Springer, USA

Galliano D., Roux P, Soulié N., 2011, «ICT Intensity of Use and the Geography of Firms » Environment and Planning A, 43(1):67-86

Gambetta D., 1988, Trust, Oxford: Oxford University Press.

Goffman E., 1974, Frame analysis: An essay on the organization of experience. Cambridge, MA: Harvard University Press

Golledge RG., 2008, "Behavioral geography and the theoretical/quantitative revolution", Geographical Analysis, Vol. 40(3): 239-58.

Gould P., White R., 1974, Mental maps, Harmondsworth : Penguin

Josset JM., Rallet A., 2017, « Numérique et transport : observer et mesurer des formes plus complexes de perception du temps de transport », Terminal [Online], 121 http://journals.openedition.org/terminal/1724 ; DOI : 10.4000/terminal.1724

Kaufman V., 2002, Re-thinking mobility, Burlington, Ashgate

Lorenz, E. 1992. 'Trust and the Theory of Industrial Districts.' in M. Storper and AJ Scott, eds, Pathways to Industrialization and Regional Development, London: Routledge

Lyons G., Urry J., 2005, « Travel time use in the information age », Transportation Research Part A: Policy and Practice, Vol. 39 (2-3), 257-276

Maskell P., Malmberg A., 1999, "Localised learning and industrial competitiveness", Cambridge Journal of Economics, Vol. 23 (2), 167-185.

Moktarian P., 2009, "If telecommunication is such a good substitute for travel, why does congestion continue to get worse? », Transportation Letters: The International Journal of Transportation Research, 1, 1-17

Mooney, S., Sherman M., and Lo Priesto C., 1991 "Academic locus of control, self- esteem, and perceived distance from home as predictors of college adjustment", Journal of Counseling \& Development, Vol. 69, pp. 445-448.

Morgan K., 2004, « The exaggerated death of geography: learning, proximity and territorial innovation systems », Journal of Economic Geography, 4 (1), 3-21,

Nohria N., Eccles R, 1992, Networks and Organizations: Structure, Form and Action. Boston: Harvard Business School Press. 
O'Brien R., 1990, « The end of geography? The impact of technology and capital flows », The AMEX Bank Review, Vol. 17, 29 May

O'Brien R., 1992, Global Financial Integration: The End of Geography, London, Royal Institute of International Affairs, Pinter Publishers

O’Leary M., Wilson J.M., Metiu A., 2014. "Beyond Being There: The Symbolic Role of Communication and Identification in Perceptions of Proximity to Geographically Dispersed Colleagues," MIS Quarterly, Vol. 38 (4), 119-1243.

Oldenburg R., 1989, The Great Good Place: Cafes, Coffee Shops, Community Centers, Beauty Parlors, General Stores, Bars, Hangouts, and How They Get You Through the Day. New York: Paragon House

Ponds R., Van Oort F., Frenken K., 2007, « The geographical and institutional proximity of research collaboration », Regional Science, Vol. 86 (3), 423-443.

Rallet A., Torre A. 2017, « Geography of innovation, proximity and beyond », in Bathelt H., Cohendet P., Henn S., Simon L. (eds.), The Elgar Companion to Innovation and Knowledge Creation, Edward Elgar Publishing, 840p.

Storper M. Venables A., 2004, "Buzz: Face-to-face contact and the urban economy ", Journal of Economic Geography, Vol. 4 (4), 351-370

Torre A., 2014, Proximity relations at the heart of territorial development processes. From clusters, spatial conflicts and temporary geographical proximity to territorial governance, in Torre A., Wallet F. (eds), 2014, Regional development and proximity relations, New Horizons in regional Science, Edward Elgar, London, 375p

Torre A., 2008, "On the role played by temporary geographical proximity in knowledge transmission", Regional Studies, 42(6), 869-889

Torre A., Rallet A., 2005, "Proximity and localization", Regional Studies, Vol. 39, n 1, 4760

Urry J., 2002, "Mobility and Proximity”, Sociology, Vol. 36, 255-274

Wilson J.M., Boyer O'Leary M., Metiu A, Quintus R. Jett Q.R, "Perceived Proximity in Virtual Work: Explaining the Paradox of Far-but-Close”, Organization Studies, 29(07): 9791002

Winger AR., 2005, "Face-to-face communication: Is it really necessary in a digitizing world?”, Business Horizons, Vol. 48 (3), 247-253

Zenker A., 2007, Innovation, perception and regions: Are perceptions of the environment related to firms' innovation behaviours? The cases of Alsace and Baden, Doctoral Dissertation, Université Louis Pasteur, Strasbourg. 